\title{
Desenvolvimento de gemas florais, florada, fotossíntese e produtividade de cafeeiros em condições de sombreamento
}

\author{
Heverly Morais ${ }^{(1)}$, Celso Jamil Marur ${ }^{(1)}$, Paulo Henrique Caramori(1), Mirian Sei Koguishi(1), \\ José Carlos Gomes $^{(1)}$ e Ana Maria de Arruda Ribeiro ${ }^{(2)}$
}

\begin{abstract}
(1)Instituto Agronômico do Paraná, Caixa Postal 481, CEP 86001-970 Londrina, PR. E-mail: heverly@iapar.br, cjmarur@iapar.br, caramori@iapar.br, miriansei@iapar.br, jcgomes@iapar.br (2)Universidade Estadual de Londrina, Centro de Ciências Agrárias, Departamento de Agronomia, Caixa Postal 6001, CEP 86051-990 Londrina, PR. E-mail: arruda@uel.br
\end{abstract}

\begin{abstract}
Resumo - O objetivo deste trabalho foi avaliar a influência do sombreamento, durante o período de desenvolvimento floral, sobre as gemas florais, florada, fotossíntese e produtividade de cafeeiros. Cafeeiros adultos IAPAR 59 cultivados em Londrina, PR, foram sombreados em diferentes épocas, com malhas de sombrite com 50\% de porosidade, e comparados com cafeeiros cultivados a pleno sol. As coberturas foram colocadas sobre as plantas em intervalos mensais, de abril a agosto, e retiradas no início de outubro. A densidade e o período de sombreamento não tiveram influência sobre a quantidade de nós, em cada estádio de desenvolvimento da gema floral, época e intensidade da florada, fotossíntese e produtividade dos cafeeiros, o que indica que a interceptação de até 50\% da radiação, incidente no período de abril a agosto, época de desenvolvimento floral, não afeta o potencial produtivo desta cultura.
\end{abstract}

Termos para indexação: Coffea arabica, fisiologia, floração, sombra artificial.

\section{Floral buds development, flowering, photosynthesis and yield of coffee plants under shading conditions}

\begin{abstract}
The objective of this paper was to evaluate the influence of shading, during the period of floral development, on floral bud, flowering, photosynthesis and grain yield of coffee plants. Adult plants IAPAR 59, grown in Londrina, Paraná State, Brazil, were shaded in different periods, with shading screens with 50\% porosity, and compared to open-grown plants. The shading screens were placed in monthly intervals, from April to August, and were all removed in the beginning of October. Shading density and period did not influence the amount of nodes in each event of development on floral bud, period and intensity of flowering, photosynthesis and grain yield of the coffee plants, which indicates that the interception of until 50\% incident radiation, during the period of floral development, does not affect the yield potential of this crop.
\end{abstract}

Index terms: Coffea arabica, physiology, flowering, artificial shade.

\section{Introdução}

Para o sucesso da atividade agrícola, é necessário o conhecimento dos fatores do meio físico que afetam os processos fisiológicos e fenológicos das plantas. No cafeeiro, o início de sua fase reprodutiva ocorre com a indução das gemas, as quais se desenvolvem nas axilas foliares dos ramos formados na estação anterior. Todo esse processo compreende uma seqüência de eventos de natureza morfológica, bioquímica e fisiológica (Camargo \& Camargo, 2001). Moens (1968) dividiu o desenvolvimento floral do cafeeiro nas seguintes etapas: indução, iniciação, diferenciação, crescimento/ desenvolvimento, latência e antese. Cada uma dessas etapas é afetada por fatores endógenos e exógenos como: fotoperíodo (Cannell, 1985), temperatura (Cannell, 1985), disponibilidade hídrica (Cannell, 1975), fitormônios como giberelina e ácido abscísico (Kumar, 1979).

No Brasil, o desenvolvimento floral dos cafeeiros ocorre em época sujeita às geadas, cuja ocorrência moderada ou severa, nessa fase, sem utilização de medidas de proteção, implica em graves prejuízos na produção do ano seguinte. Nesse caso, o sombreamento vem sendo utilizado como alternativa para o problema, com uso da cobertura que intercepta a radiação de ondas longas, emitidas pelo solo e cafeeiros, e impede 
resfriamentos intensos (Morais et al., 2006). Arborizações de cafeeiros com grevílea, leucena, bracatinga, pínus e guandu contribuíram para minimizar danos provocados por geadas no Norte do Paraná (Leal, 2004; Morais et al., 2006).

O sombreamento provoca alterações no microclima e, em razão da plasticidade do cafeeiro, pode afetar sua anatomia (Morais et al., 2003) e fisiologia (Morais et al., 2004), e influenciar no processo de indução, diferenciação floral e antese. Os impactos dependem do tipo, densidade, duração e época de sombreamento, bem como das condições climáticas vigentes. Morais et al. (2006) avaliaram cafeeiros, densamente sombreados com guandu, durante a fase de crescimento do ramo plagiotrópico, e encontraram menor número de nós por ramo e menor número de frutos por nó. Morais et al. (2004) estudaram folhas de cafeeiros densamente sombreados, diferenciadas anatomicamente de plantas cultivadas a pleno sol, e observaram que aquelas apresentavam menor número de estômatos, menor densidade do mesofilo (grande quantidade de espaços intercelulares) e células das cutículas e paredes celulares mais finas. Maiores taxas fotossintéticas foram encontradas em folhas de cafeeiros formadas a pleno sol, em comparação a folhas formadas sob sombreamento denso (Morais et al., 2003).

Em conseqüência das adaptações nos processos morfológicos e metabólicos, os cafeeiros cultivados sob intensas radiações tendem a apresentar maior produção (Morais et al., 2006). Assim, ao mesmo tempo em que é necessária a proteção dos cafeeiros contra geadas, é também fundamental que sejam observados os níveis e as épocas adequadas de sombreamento, para que este não afete economicamente a produção. Para tanto, são essenciais os estudos sobre o manejo de sombreamento como densidade, época, duração e sua interferência no desenvolvimento reprodutivo do cafeeiro. Na prática, tais conhecimentos podem auxiliar na distribuição da colheita, na estimativa da necessidade de mão-de-obra, no planejamento das práticas culturais, no manejo de pragas e doenças, na proteção contra estresses abióticos e na identificação de alternativas para a melhoria da qualidade do fruto (Camayo et al., 2003).

O objetivo deste trabalho foi avaliar a influência do sombreamento, durante algumas fases do desenvolvimento do floral, sobre as gemas florais, florada, fotossíntese e produtividade de cafeeiros.

\section{Material e Métodos}

O experimento foi desenvolvido no campo experimental do Iapar, em Londrina, PR, a $610 \mathrm{~m}$ de altitude, $23^{\circ} 23^{\prime} \mathrm{S}$ e $50^{\circ} 11^{\prime} \mathrm{W}$. O solo é um Latossolo Vermelho eutroférrico (Embrapa, 1999), com 82\% de argila. O clima da região é do tipo $\mathrm{Cfa}$, caracterizado como clima subtropical úmido, com verão quente, conforme Köppen. A temperatura média anual é de $21^{\circ} \mathrm{C}$, e a média do mês mais quente (janeiro) é de $24^{\circ} \mathrm{C}$ e a do mês mais frio (junho) $17^{\circ} \mathrm{C}$. A precipitação média anual é de $1.500 \mathrm{~mm}$, dezembro, janeiro e fevereiro são os meses mais chuvosos e junho, julho e agosto os mais secos (Caviglione et al., 2000).

Foram avaliados cafeeiros da espécie Coffea arabica L. da cultivar IAPAR 59, plantados em junho de 1993, em espaçamento 2,5x1,5 m, com duas plantas por cova; em outubro de 2000, foram recepados em decorrência de geada. Malhas de sombreamento do tipo "sombrite" - com 50\% de porosidade e dimensão de $12 \mathrm{~m}$ de comprimento, 7,5 $\mathrm{m}$ de largura e 2,5 $\mathrm{m}$ de altura - foram utilizadas para cobrir os cafeeiros no início dos seguintes meses (tratamentos): abril (T1), maio (T2), junho (T3), julho (T4) e agosto (T5) de 2004, com um tratamento sem cobertura como controle (T6). As coberturas de todos os tratamentos foram retiradas, simultaneamente, no início de outubro do mesmo ano.

O delineamento experimental utilizado foi o inteiramente casualizado, com quatro repetições. Cada parcela constou da cobertura de três linhas de cafeeiros, com oito covas cada. Em cada parcela, foram avaliadas quatro plantas da linha central. Para tanto, foram marcados e avaliados dois ramos localizados no terço superior de cada planta: um voltado para a direção norte e outro para a direção sul. Nos ramos marcados, oito nós produtivos, formados no ano anterior, foram avaliados por meio de observações visuais externas do tamanho das gemas florais e quantidade de flores, nas seguintes datas: $8 / 5,27 / 5,22 / 6,21 / 7,20 / 8,15 / 9,20 / 9$, 27/9, 20/10 e 24/11/2004.

A identificação e classificação das fases do desenvolvimento, da gema floral do cafeeiro, foram subdivididas em: $G_{1}$, nó indiferenciado; $G_{2}$, intumescimento do nó; $\mathrm{G}_{3}$, gema com até $3 \mathrm{~mm} ; \mathrm{G}_{4}$, gema com 3,1 a $6 \mathrm{~mm}$; $\mathrm{G}_{5}, 6$ a $10 \mathrm{~mm}$ (botão floral verde); $\mathrm{G}_{6}$, maior que $10 \mathrm{~mm}$ (botão floral branco). 
Os dados de precipitação foram obtidos na estação meteorológica do Iapar, a $100 \mathrm{~m}$ da área experimental. $\mathrm{O}$ balanço de água no solo foi realizado pelo modelo SIMBA (simulação de balanço de água), segundo Faria \& Madramootoo (1996). Consideraram-se a profundidade do perfil do solo de $80 \mathrm{~cm}$ e a taxa de $10 \%$ de água disponível, que caracterizou uma capacidade de água disponível (CAD) de $80 \mathrm{~mm}$. Com base na percentagem de água disponível no solo, dividiu-se o período analisado em três situações: excesso, quando a água disponível no solo ultrapassou $100 \%$ da capacidade máxima; retirada/reposição, quando a água disponível no solo situou-se entre $50 \mathrm{e}$ $100 \%$; e deficit, quando a água disponível no solo foi inferior a $50 \%$.

Foi instalada uma estação meteorológica no local do experimento, da qual se obtiveram os dados de umidade e temperatura do ar, com um sensor HMP45C, $20 \mathrm{~cm}$ acima das plantas e a 2,3 $\mathrm{m}$ da superfície.

Os dados de desenvolvimento da gema floral e da florada foram submetidos à análise de variância e as médias ao teste de Tukey, a 5\% de probabilidade, com o SAS (SAS Institute, 1989).

Para a avaliação da fotossíntese, foram utilizadas três plantas de cada tratamento, escolhidas ao acaso. As medidas foram realizadas nos dias 16/6/2004 (T1, T2, T6); 23/6/2004 (T1, T2, T6) e 9 e 10/9/2004 (todos os tratamentos). As avaliações foram efetuadas das 9 às $16 \mathrm{~h}$. Em razão da nebulosidade, a fotossíntese não foi medida em alguns horários. Foram selecionadas folhas correspondentes ao terceiro par, a partir do ápice do ramo plagiotrópico, plenamente expostas à luz solar e orientadas no sentido leste/ oeste, em relação à luz solar incidente. Em duas folhas de cada planta, procedeu-se à avaliação de fotossíntese líquida, por meio de um sistema portátil de fotossíntese (LI-COR, modelo LI-6200 e analisador de gás LI-6250). Os dados fornecidos pela câmara de fotossíntese foram processados conforme Marur \& Vieira (1997). A comparação estatística entre os tratamentos foi feita pelo teste $\mathrm{F}$, a $5 \%$ de probabilidade.

A produtividade dos cafeeiros foi obtida pela colheita de grãos em 12 plantas por parcela, que foram pesados imediatamente e corrigidos para $13 \%$ de umidade em base massa de matéria seca. Após a análise de variância, as médias foram comparadas pelo teste de Tukey, a 5\% de probabilidade.

\section{Resultados e Discussão}

Não houve diferenças significativas, entre os tratamentos, quanto à quantidade de nós em cada estádio do desenvolvimento da gema floral (Tabela 1), ou seja, houve homogeneidade no desenvolvimento das gemas florais, tanto nos cafeeiros cultivados a pleno sol (T6), como nos sombreados nas diferentes épocas (T1, T2, T3, T4 e T5). Também não foram observados deslocamentos (atraso ou avanço), em nenhuma etapa do desenvolvimento das gemas $\left(\mathrm{G}_{1}\right.$ a $\left.\mathrm{G}_{6}\right)$. Isso pode ter ocorrido, porque as plantas não estavam sombreadas no momento da indução (janeiro-fevereiro) ou durante o crescimento dos nós (setembro-dezembro), e essas condições podem ter sido as desencadeadoras das mudanças do desenvolvimento vegetativo.

As principais floradas ocorreram depois de períodos de deficiência hídrica acentuada seguida de intensas precipitações: $35,2 \mathrm{~mm}$ no segundo decêndio de setembro/2004, e 155,5 mm no segundo decêndio de outubro/2004 (Figura 1). Além disso, o aumento da umidade relativa do ar e a diminuição da temperatura do ar também podem ter contribuído para a floração (Figura 2). Mes (1957) relata que a precipitação associada à queda repentina da temperatura do ar pode contribuir para a interrupção da dormência dos botões. Outros autores também observaram a ocorrência de antese após a precipitação (Gouveia, 1984; Camargo \& Camargo, 2001; Pezzopane et al., 2003). O sombreamento dos cafeeiros, nas diferentes épocas, não provocou alterações nas datas da antese e na quantidade de flores das três floradas (Figura 3).

Jaramillo-Botero et al. (2006), em estudos de sombreamento artificial, durante todo o ciclo de Coffea arabica com a mesma idade das plantas do presente experimento, encontraram $30 \%$ a mais de botões florais em plantas sob bloqueio de $48 \%$ da radiação fotossintética, comparadas às não sombreadas. Todavia, existem evidências de que o sombreamento pode reduzir a indução floral e o número de flores (Cannell, 1975). A respeito disso, na Colômbia, Castillo \& López (1966) observaram em Coffea arabica, sob diferentes percentagens de sombreamento artificial $(100,75,50 \mathrm{e}$ $25 \%$ ), maior número de nós com flores e maior número de flores por nó nos ramos laterais, à medida que se incrementava a radiação solar. Para Kumar (1979), a menor diferenciação de gemas florais em cafeeiros devese ao aumento do nível endógeno do fitormônio 
giberelina, que tem efeito inibidor na formação de gemas florais. Este autor observou que em cafeeiros adensados (6.000 plantas por hectare), há expressivo aumento na atividade da giberelina, menor indução e diferenciação de gemas florais e menor capacidade produtiva. Com a aplicação do inibidor do crescimento CCC (cloreto 2-cloroetil-trimetilamônio), que restringe a biossíntese de giberelinas, houve aumento de $30-35 \%$ na produtividade (Kumar, 1979).

Nos estudos de cafeeiros sombreados, é difícil comparar os efeitos sobre o desenvolvimento floral e o número de flores, em razão das diferenças nas condições experimentais, em que se destacam o tipo de cobertura (natural ou artificial), densidade, duração e época de sombreamento; condições climáticas vigentes e o clima local; genótipo testado e idade das plantas, entre outros. Neste trabalho, as plantas sombreadas podem ter sido beneficiadas com o alto potencial produtivo (que foi igual estatisticamente às cultivadas a pleno sol), em consequiência da cobertura com tela de sombrite, sob a qual não houve competição por água, como ocorre com algumas árvores sombreadoras; também pelo sombreamento parcial que fez incidir radiação dentro da faixa adequada para os cafeeiros; e pela cobertura

Tabela 1. Quantidade de nós, em diferentes estádios de desenvolvimento da gema floral de cafeeiros $\left(\mathrm{G}_{1}\right.$ a $\left.\mathrm{G}_{6}\right)$, sombreados no início de abril (T1), maio (T2), junho (T3), julho (T4) e agosto (T5), e sem sombreamento (T6) ${ }^{(1)}$.

\begin{tabular}{|c|c|c|c|c|c|c|c|c|c|}
\hline Estádio & Tratamento & 8/maio & $27 /$ maio & 22/jun. & 21/jul. & 20/ago. & $15 /$ set. & $20 /$ set. & Total \\
\hline Nó indiferenciado & 1 & $73 a$ & $46 a$ & $11 \mathrm{a}$ & $1 \mathrm{a}$ & $0 \mathrm{a}$ & $0 \mathrm{a}$ & $0 \mathrm{a}$ & 265 \\
\hline \multirow[t]{5}{*}{$\left(G_{1}\right)$} & 2 & - & $31 \mathrm{a}$ & $6 a$ & $2 \mathrm{a}$ & $0 \mathrm{a}$ & $0 \mathrm{a}$ & $0 \mathrm{a}$ & \\
\hline & 3 & - & - & - & $1 \mathrm{a}$ & $0 \mathrm{a}$ & $1 \mathrm{a}$ & 1a & \\
\hline & 4 & - & - & - & $0 \mathrm{a}$ & $0 \mathrm{a}$ & $0 \mathrm{a}$ & $0 \mathrm{a}$ & \\
\hline & 5 & - & - & - & - & $8 \mathrm{~b}$ & $5 b$ & $5 b$ & \\
\hline & 6 & $46 a$ & $24 a$ & $6 a$ & $1 \mathrm{a}$ & $1 \mathrm{a}$ & $0 \mathrm{a}$ & $0 \mathrm{a}$ & \\
\hline \multirow{6}{*}{$\begin{array}{l}\text { Intumescimento do } \\
\text { nó }\left(G_{2}\right)\end{array}$} & 1 & $102 a$ & $70 \mathrm{a}$ & $49 a$ & $22 \mathrm{a}$ & $4 a$ & $2 \mathrm{a}$ & $2 \mathrm{a}$ & 654 \\
\hline & 2 & - & $64 a$ & $42 \mathrm{a}$ & $16 \mathrm{a}$ & $2 \mathrm{a}$ & $2 \mathrm{a}$ & $2 \mathrm{a}$ & \\
\hline & 3 & - & - & - & $21 \mathrm{a}$ & $8 \mathrm{a}$ & $3 a$ & $3 a$ & \\
\hline & 4 & - & - & - & $8 \mathrm{a}$ & $1 \mathrm{a}$ & $1 \mathrm{a}$ & 1a & \\
\hline & 5 & - & - & - & - & $3 a$ & $2 \mathrm{a}$ & $2 \mathrm{a}$ & \\
\hline & 6 & $100 \mathrm{a}$ & $60 \mathrm{a}$ & $31 \mathrm{a}$ & $10 \mathrm{a}$ & $3 a$ & $3 a$ & $3 a$ & \\
\hline Gema com até & 1 & $81 \mathrm{a}$ & $140 \mathrm{a}$ & $156 a$ & $82 a$ & $41 \mathrm{a}$ & $10 \mathrm{a}$ & $10 \mathrm{a}$ & 2.056 \\
\hline \multirow{4}{*}{$3 \mathrm{~mm}\left(\mathrm{G}_{3}\right)$} & 2 & - & $161 \mathrm{a}$ & $187 \mathrm{a}$ & $152 \mathrm{a}$ & $43 a$ & $5 a$ & $4 a$ & \\
\hline & 4 & - & - & - & $111 \mathrm{a}$ & $18 \mathrm{a}$ & $2 \mathrm{a}$ & 1a & \\
\hline & 5 & - & - & - & - & $36 a$ & $14 \mathrm{a}$ & $5 a$ & \\
\hline & 6 & $110 \mathrm{a}$ & $172 \mathrm{a}$ & $151 \mathrm{a}$ & $102 a$ & $21 \mathrm{a}$ & $7 \mathrm{a}$ & $6 a$ & \\
\hline Gema com 3,1 a & 1 & - & - & $40 \mathrm{a}$ & $151 \mathrm{a}$ & $200 a$ & $29 a$ & $19 a$ & 2.208 \\
\hline \multirow[t]{5}{*}{$6 \mathrm{~mm}\left(\mathrm{G}_{4}\right)$} & 2 & - & - & $21 \mathrm{a}$ & $86 a$ & $194 a$ & $46 \mathrm{a}$ & $11 \mathrm{a}$ & \\
\hline & 3 & - & - & - & $88 \mathrm{a}$ & $191 \mathrm{a}$ & $46 a$ & $17 \mathrm{a}$ & \\
\hline & 4 & - & - & - & $133 a$ & $226 a$ & $21 \mathrm{a}$ & $5 a$ & \\
\hline & 5 & - & - & - & - & $178 \mathrm{a}$ & $34 a$ & $13 a$ & \\
\hline & 6 & - & - & $68 \mathrm{a}$ & $134 a$ & $203 a$ & $19 a$ & $11 \mathrm{a}$ & \\
\hline \multirow{6}{*}{$\begin{array}{l}\text { Botão floral verde } \\
\left(\mathrm{G}_{5}\right)\end{array}$} & 1 & - & - & - & $0 \mathrm{a}$ & $11 \mathrm{a}$ & $215 a$ & $31 \mathrm{a}$ & 1.744 \\
\hline & 2 & - & - & - & $0 \mathrm{a}$ & $17 \mathrm{a}$ & $203 a$ & $67 a$ & \\
\hline & 3 & - & - & - & $1 \mathrm{a}$ & $7 \mathrm{a}$ & $194 a$ & $67 \mathrm{a}$ & \\
\hline & 4 & - & - & - & $4 a$ & $11 \mathrm{a}$ & $232 \mathrm{a}$ & $49 a$ & \\
\hline & 5 & - & - & - & - & $31 \mathrm{a}$ & $201 a$ & $55 a$ & \\
\hline & 6 & - & - & - & $9 a$ & $28 \mathrm{a}$ & $227 \mathrm{a}$ & $54 a$ & \\
\hline \multirow{4}{*}{$\begin{array}{l}\text { Botão floral branco } \\
\left(\mathrm{G}_{6}\right)\end{array}$} & 3 & - & - & - & - & - & - & $165 a$ & \\
\hline & 4 & - & - & - & - & - & - & $200 \mathrm{a}$ & \\
\hline & 5 & - & - & - & - & - & - & $176 a$ & \\
\hline & 6 & - & - & - & - & - & - & $182 \mathrm{a}$ & \\
\hline
\end{tabular}

${ }^{(1)}$ Médias com letras iguais não diferem entre si, na coluna - dentro do mesmo estádio -, pelo teste de Tukey, a 5\% de probabilidade. 
sazonal ou ausência de sombreamento no período de indução floral (janeiro-fevereiro) e formação dos ramos e folhas (setembro-março). $\mathrm{O}$ fato de o sombreamento parcial, durante o outono-inverno, não ter afetado a formação das estruturas reprodutivas é um dado relevante, pois é justamente nesse período que se necessita proteger as lavouras contra geadas.

As maiores taxas fotossintéticas ocorreram no período da manhã, entre 9 e 10h, com média geral, em todos os tratamentos e todos os dias, de 3,2, 2,6 e 1,5 $\mu \mathrm{mol}$ $\mathrm{CO}_{2} \mathrm{~m}^{-2} \mathrm{~s}^{-1}$, no horário das 9 às $10,10 \mathrm{~h} 30$ às $12 \mathrm{e} 13 \mathrm{~h} 30$ às $14 \mathrm{~h} 30$, respectivamente (Tabela 2). Marur \& Faria (2006) avaliaram folhas individuais de cafeeiros a pleno sol, e também encontraram máximas taxas fotossintéticas nas primeiras horas da manhã, que depois, com o aumento da radiação, diminuíram constantemente até o final do dia. Sob altas radiações e temperaturas, a fotossíntese diminui, principalmente porque os estômatos se fecham para a planta não perder água (DaMatta, 2004).

Nas avaliações de junho, época em que havia suprimento hídrico satisfatório (Figura 1), as taxas de fotossíntese foram mais elevadas, com média geral, em todos os horários e tratamentos, de 3 e $4,43 \mu \mathrm{mol} \mathrm{CO} \mathrm{Cm}^{-2} \mathrm{~s}^{-1}$ para os dias 16 e 23 , respectivamente. No mês de setembro, período com deficiência hídrica (Figura 1), a taxa fotossintética média em todos os horários e tratamentos foi de $1,36 \mu \mathrm{mol} \mathrm{CO} \mathrm{Cm}^{-2} \mathrm{~s}^{-1}$ (Tabela 2). Isso evidencia a influência direta da disponibilidade hídrica na fotossíntese dos cafeeiros. DaMatta (2004) sugere que a alta demanda evaporativa é o responsável direto pelo fechamento estomático, que por sua vez acarreta aumentos adicionais na temperatura foliar. Assim, a

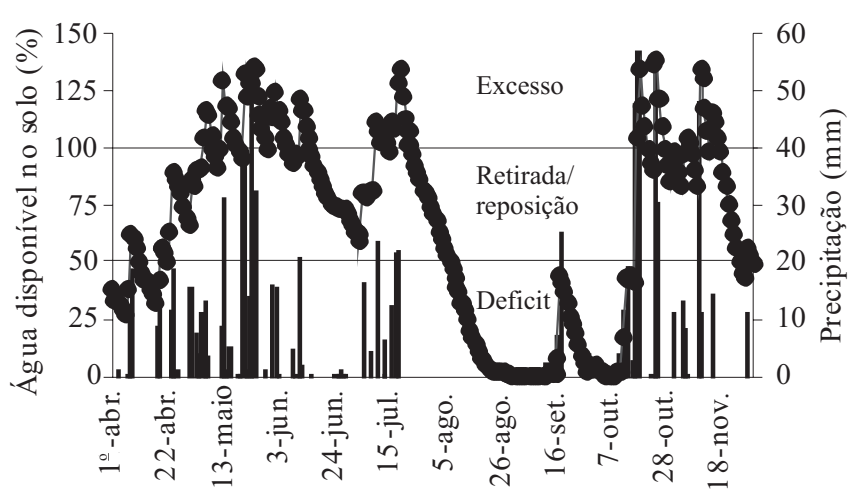

Figura 1. Variação da água disponível no solo, na zona radicular do cafeeiro $(0-80 \mathrm{~cm})$, e precipitação. fotossíntese líquida é reduzida em função de limitações estomáticas; além disso, há possibilidade de ocorrência de danos diretos às estruturas fotossintéticas causados pelas altas temperaturas.

A fotossíntese líquida não apresentou, de maneira geral, diferenças significativas entre os tratamentos, ou seja, o sombreamento não afetou a fotossíntese (Tabela 2). Isso provavelmente ocorreu, porque as folhas sombreadas foram formadas na estação anterior, a pleno sol, portanto tinham as estruturas anatômicas adaptadas a altos níveis de radiação, como: grande número de estômatos; atividades de abertura e fechamento dos estômatos mais intensos; e facilidade de o $\mathrm{CO}_{2}$ se difundir nos espaços intercelulares (Morais et al., 2004). Segundo Larcher (2000), as folhas se adaptam e modificam suas estruturas internas, de acordo com as condições médias de radiação, preponderantemente

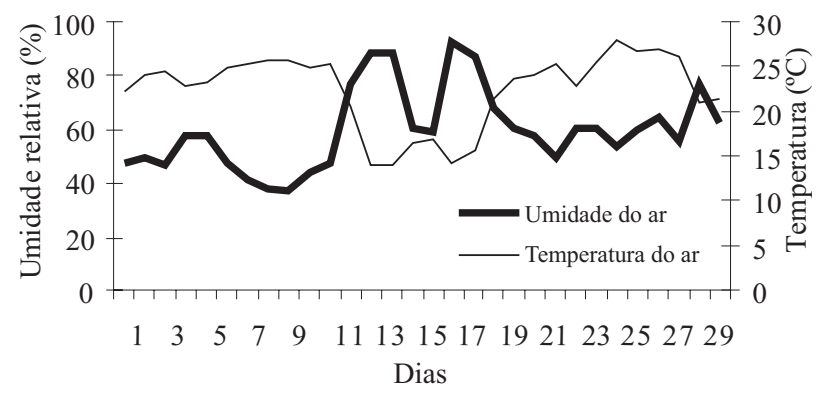

Figura 2. Média diária da umidade relativa do ar e temperatura do ar, em setembro de 2004, em Londrina, PR.

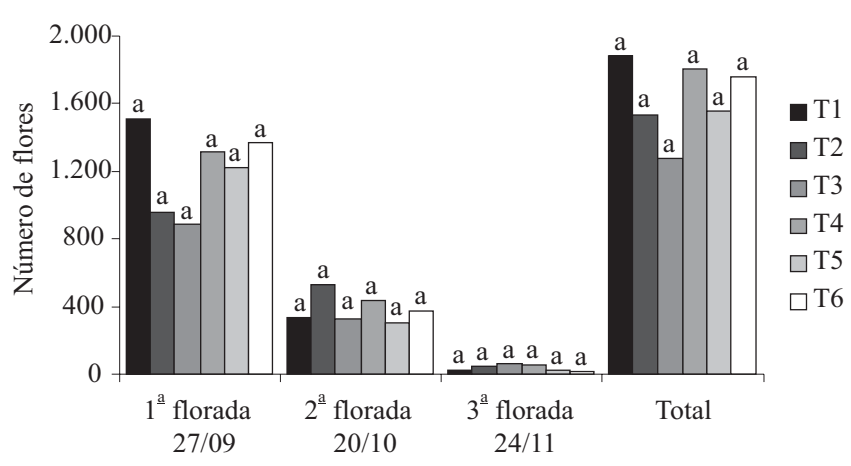

Figura 3. Número total de flores, por tratamento, em cafeeiros sombreados no início de abril (T1), maio (T2), junho (T3), julho (T4), agosto (T5), e sem sombreamento (T6). Médias com letras iguais não diferem entre si, pelo teste de Tukey, a $5 \%$ de probabilidade. 
durante a morfogênese, o que resulta nas folhas chamadas de sol e de sombra, em uma mesma espécie, e esta diferenciação fenotípica dos tecidos é irreversível. Paiva (2001) encontrou maiores taxas de fotossíntese em mudas de cafeeiros cultivados em viveiros com 50\% de sombreamento, em comparação às mudas cultivadas a pleno sol. Freitas et al. (2003) observaram maiores taxas de fotossíntese nas linhas de cafeeiros mais próximas das seringueiras, ou seja, nos cafeeiros mais sombreados, em razão do menor deficit de pressão de vapor. Kumar \& Tieszen (1980) encontraram menores valores de fotossíntese, em plantas cultivadas a pleno sol, em comparação às sombreadas. No entanto, experiências na Costa Rica (Cannell, 1975) e no Brasil (Carelli et al., 1999) demonstraram que a fotossíntese é menor em cafeeiros cultivados em condições sombreadas.

Outro fator que pode ter contribuído para potencializar o aproveitamento da luminosidade, pelas plantas sombreadas, e não afetar a fotossíntese, foi a radiação difusa, a qual pode ser proporcionalmente maior sob a cobertura. Segundo Martinez (1978), em dias sem nuvens, a radiação difusa correspondeu a 60 e $20 \%$ no interior e exterior de uma estufa, respectivamente. Nutman (1937) demonstrou, na África, que a atividade fotossintética no cafeeiro foi muito menor quando

Tabela 2. Fotossíntese líquida $\left(\mu \mathrm{mol} \mathrm{CO} \mathrm{Cm}^{-2} \mathrm{~s}^{-1}\right)$, medida no decorrer do dia, em plantas de Coffea arabica sombreadas em abril (T1), maio (T2), junho (T3), julho (T4), agosto (T5), e sem sombreamento $(\mathrm{T} 6)^{(1)}$.

\begin{tabular}{|c|c|c|c|c|}
\hline Tratamento & $\begin{array}{l}9 \text { às } \\
10 \mathrm{~h}\end{array}$ & $\begin{array}{c}10 \mathrm{~h} 30 \text { às } \\
12 \mathrm{~h}\end{array}$ & $\begin{array}{c}13 \mathrm{~h} 30 \text { às } \\
14 \mathrm{~h} 30\end{array}$ & $\begin{array}{c}14 \mathrm{~h} 30 \text { às } \\
16 \mathrm{~h}\end{array}$ \\
\hline & \multicolumn{4}{|c|}{$16 / 06$} \\
\hline $\mathrm{T} 1$ & $4,67 \mathrm{a}$ & $4,42 \mathrm{a}$ & $3,66 \mathrm{a}$ & - \\
\hline $\mathrm{T} 2$ & $2,90 \mathrm{~b}$ & $3,24 \mathrm{a}$ & $1,45 b$ & - \\
\hline T6 & $3,07 \mathrm{ab}$ & $2,29 \mathrm{a}$ & $1,22 b$ & - \\
\hline & \multicolumn{4}{|c|}{$23 / 06$} \\
\hline $\mathrm{T} 1$ & $4,96 \mathrm{ab}$ & $5,15 \mathrm{a}$ & $3,03 \mathrm{a}$ & $2,76 \mathrm{a}$ \\
\hline $\mathrm{T} 2$ & $4,44 b$ & $4,95 \mathrm{a}$ & $3,24 \mathrm{a}$ & $2,88 \mathrm{a}$ \\
\hline $\mathrm{T} 6$ & $6,11 \mathrm{a}$ & $4,35 \mathrm{a}$ & $3,60 \mathrm{a}$ & $3,51 \mathrm{a}$ \\
\hline & \multicolumn{4}{|c|}{9 e $10 / 09$} \\
\hline $\mathrm{T} 1$ & $2,75 a$ & $1,35 \mathrm{a}$ & $0,19 \mathrm{a}$ & - \\
\hline $\mathrm{T} 2$ & $2,02 \mathrm{a}$ & $0,68 \mathrm{a}$ & $0,67 \mathrm{a}$ & - \\
\hline T3 & $2,99 a$ & $2,16 \mathrm{a}$ & $0,55 \mathrm{a}$ & - \\
\hline T4 & $2,37 \mathrm{a}$ & $1,51 \mathrm{a}$ & $0,43 a$ & - \\
\hline T5 & $2,31 \mathrm{a}$ & $1,84 \mathrm{a}$ & $0,53 \mathrm{a}$ & - \\
\hline T6 & $1,84 \mathrm{a}$ & $1,09 \mathrm{a}$ & $0,44 \mathrm{a}$ & - \\
\hline
\end{tabular}

(1)Médias seguidas por letras iguais, na coluna, na mesma data, não diferem entre si, a $5 \%$ de probabilidade, pelo teste F. exposta à plena luz solar, quando comparada a plantas sob luz difusa de menor intensidade, sob coberturas de baixa densidade. De acordo com Martinez (1978), a radiação difusa é mais efetiva para a fotossíntese, por ser multidirecional e penetrar melhor entre as plantas, o que pode compensar, em parte, a interceptação da radiação fotossintética. Nota-se que há grande variabilidade, entre os estudos realizados com fotossíntese em cafeeiros sombreados, em consequiência das diferenças nas condições experimentais sob regimes distintos de radiação solar, temperatura e disponibilidade hídrica.

A produtividade média de grãos de café não foi afetada pelo sombreamento artificial realizado nas diferentes épocas do desenvolvimento das gemas florais (Figura 4). Isso ocorreu, provavelmente, em razão do crescimento dos nós produtivos da estação anterior ao sombreamento. De acordo com Gouveia (1984), a produção depende da interação entre o número de nós formados na estação de crescimento e as condições ambientais favoráveis à diferenciação das gemas florais. Jaramillo et al. (2006) avaliaram o sombreamento artificial, durante todo o ciclo reprodutivo do cafeeiro, e encontraram maior produção em plantas sob $48 \%$ de bloqueio da radiação fotossinteticamente ativa e com menor quantidade de fertilizantes. Sistemas de cultivos consorciados, com atenuações de aproximadamente $20 \%$ de radiação solar global, não produziram efeitos negativos na produção de café (Pezzopane, 2004).

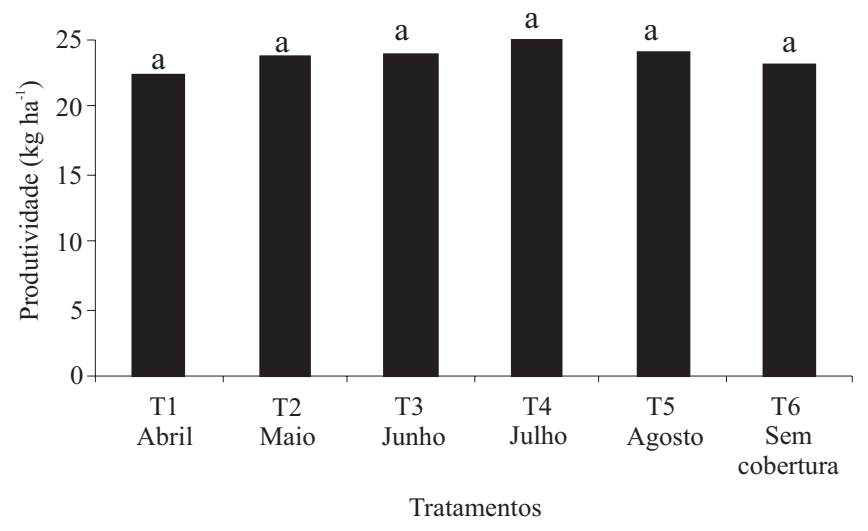

Figura 4. Rendimento de grãos de cafeeiros, sombreados artificialmente em diferentes épocas, na safra de 2005. Médias com letras iguais não diferem entre si pelo teste de Tukey, a $5 \%$ de probabilidade. 
Apesar de o cafeeiro ser considerado uma planta de alta plasticidade, capaz de alterar seu desenvolvimento reprodutivo com base na intensidade da radiação solar que atinge sua copa, os resultados mostram que houve consonância, entre os tratamentos, na época das floradas, quantidade de flores, taxas fotossintéticas e produtividade. Todavia, as causas desses resultados ainda não estão totalmente elucidadas, e supõe-se que a quantidade ou a qualidade de luz, ou a época de sombreamento, não afetou o desenvolvimento dos cafeeiros, ou ainda que outros fatores como número de nós e o aparato fotossintético das folhas formadas a pleno sol, na estação anterior, não limitaram o desenvolvimento dos botões florais e, conseqüentemente, a florada e produção.

\section{Conclusões}

1. O sombreamento artificial dos cafeeiros, em diferentes épocas, com interceptação de $50 \%$ da radiação solar global, durante o período de desenvolvimento floral, não provoca alterações na quantidade de nós em cada estádio de desenvolvimento da gema floral, épocas das floradas, quantidades de flores e produtividade.

2. As taxas fotossintéticas apresentam decréscimo no primeiro decêndio de setembro, provavelmente em consequiência do deficit hídrico no solo e da elevada demanda evaporativa atmosférica.

\section{Referências}

CAMARGO, A.P.; CAMARGO, M.B.P. Definição e esquematização das fases fenológicas do cafeeiro arábica nas condições tropicais do Brasil. Bragantia, v.60, p.65-68, 2001.

CAMAYO, V.G.C.; ARCILA, P.J. Estudio anatómico y morfológico de la diferenciación y desarrollo de las flores del cafeto $C$. arabica $\mathrm{L}$. variedad Colombia. Cenicafé, v.47, p.121-139, 1996.

CAMAYO, V.G.C.; CHAVES, C.B.; ARCILA, P.J.; JARAMILLO, R.A. Desarrollo floral del cafeto y su relación con las condiciones climáticas de Chinchiná-Caldas. Cenicafé, v.54, p.35-49, 2003.

CANNELL, M.G.R. Crop physiological aspects of coffee bean yield: a review. Journal of Coffee Research, v.5, p.7-20, 1975.

CANNELL, M.G.R. Physiology of the coffee crop. In: CLIFFORD, M.N.; WILLSON, K.C. (Ed.). Coffee: botany, biochemistry and production of beans and beverage. London: Croom Helm, 1985. p.108-134.

CARELLI, M.L.C.; FAHL, J.I.; TRIVELIN, P.C.O.; QUEIROZVOLTAN, R.B. Carbon isotope discrimination and gas exchange in coffee species grown under different irradiance regimes. Revista Brasileira de Fisiologia Vegetal, v.11, p.63-68, 1999.

CASTILLO, Z.J.; LÓPEZ, A.R. Nota sobre el efecto de la intensidad de la luz en la floración del cafeto. Cenicafé, v.17, p.51-60, 1966.

CAVIGLIONE, J.H.; CARAMORI, P.H.; KIIHL, L.B.; OLIVEIRA, D. Cartas climáticas do Paraná. Londrina: Iapar, 2000. 1 CD-ROM.

DaMATTA, F.M. Fisiologia do cafeeiro em sistemas arborizados. In: MATSUMOTO, S.N. (Org.). Arborização de cafezais no Brasil. Salvador: Uesb, 2004. p.87-118.

EMBRAPA. Sistema brasileiro de classificação de solos. Brasília: Embrapa-SPI; Rio de Janeiro: Embrapa-CNPS, 1999. 412p.

FARIA, R.T.; MADRAMOOTOO, C.A. Simulation of soil moisture profiles for wheat in Brazil. Agricultural Water Management, v.31, p.35-49, 1996.

FREITAS, R.B.; OLIVEIRA, L.E.M.; DELÚ FILHO, N.; SOARES, A.M. Influência de diferentes níveis de sombreamento no comportamento fisiológico de cultivares de café (Coffea arabica). Ciência e Agrotecnologia, v.27, p.804-810, 2003.

GOUVEIA, N.M. Estudo da diferenciação e crescimento de gemas florais de Coffea arabica L.: observações sobre antese e maturação dos frutos. 1984. 237p. Dissertação (Mestrado) Universidade Estadual de Campinas, Campinas.

JARAMILLO, C.; SANTOS, R.H.S.; MARTINEZ, H.E.P.; CECON, P.R.; SANTOS, C.R. Desenvolvimento reprodutivo e produção inicial de cafeeiros sob diferentes níveis de sombreamento e adubação. Revista Ceres, v.307, p.343-349, 2006.

KUMAR, D. Some aspects of the physiology of Coffea arabica L: a review. Kenya Coffee, v.44, p.9-47, 1979.

KUMAR, D.; TIESZEN, L.L. Photosynthesis in Coffea arabica: effects of light and temperature. Experimental Agriculture, v.16, p.13-19, 1980.

LARCHER, W. Ecofisiologia vegetal. São Carlos: RiMa, 2000. $531 \mathrm{p}$.

LEAL, A.C. Avaliação de espécies arbóreas para sistemas agroflorestais com cafeeiros no Norte do Paraná. 2004. 114p. Tese (Doutorado) - Universidade Federal do Paraná, Curitiba.

MARTINEZ, G.P.F. Características climáticas de los invernadores de plástico. Madri: Instituto Nacional de Investigaciones Agrarias, 1978. (Hojas Técnicas, 19).

MARUR, C.J.; FARIA, R.T. Photosynthesis of individual leaves in a coffee plant. Acta Scientiarium, v.28, p.331-335, 2006.

MARUR, C.J.; VIEIRA, L.G.E. Spreadsheet macros for handling data collected from the LI-6200 portable photosynthesis system. Revista Brasileira de Agrometeorologia, v.5, p.133-135, 1997.

MES, M.G. Studies on the flowering of Coffea arabica L. III. Various phenomena associated with the dormancy of coffee flower buds. Portugaliae Acta Biologica, v.5, p.25-44, 1957.

MOENS, P. Investigaciones morfológicas, ecológicas y fisiológicas sobre cafetos. Turrialba, v.18, p.209-233, 1968.

MORAIS, H.; CARAMORI, P.H.; RIBEIRO, A.M.A.; GOMES, J.C.; KOGUISHI, M.S. Microclimatic characterization and 
productivity of coffee plants grown under shade of pigeon pea in Southern Brazil. Pesquisa Agropecuária Brasileira, v.41, p.763770, 2006.

MORAIS, H.; MARUR, C.J.; CARAMORI, P.H.; RIBEIRO, A.M.A.; GOMES, J.C. Características fisiológicas e de crescimento de cafeeiro sombreado com guandu e cultivado a pleno sol. Pesquisa Agropecuária Brasileira, v.38, p.1131-1137, 2003.

MORAIS, H.; MEDRI, M.E.; CARAMORI, P.H.; RIBEIRO, A.M.A.; MARUR, C.J.; GOMES, J.C. Modifications on leaf anatomy of Coffea arabica caused by shade of pigeonpea (Cajanus cajan). Brazilian Archives of Biology and Technology, v.4, p.863871, 2004.

NUTMAN, F.J. Photosynthesis of coffee leaves under natural conditions. Annals of Botany, v.1, p.353-367, 1937.
PAIVA, L.C. Produção de mudas de cafeeiro (Coffea arabica L.) em diferentes níveis de sombreamento e seus reflexos na implantação. 2001. 112p. Dissertação (Mestrado) - Universidade Federal de Lavras, Lavras.

PEZZOPANE, J.R.M. Avaliações microclimáticas, fenológicas e agronômicas em café arábica cultivado a pleno sol e consorciado com banana 'Prata Anã'. 2004. 136p. Tese (Doutorado) - Escola Superior de Agricultura Luiz de Queiroz, Piracicaba.

PEZZOPANE, J.R.M.; PEDRO JÚNIOR, M.J.; THOMAZIELLO, R.A.; CAMARGO, M.B.P. Escala para avaliação de estádios fenológicos do cafeeiro arábica. Bragantia, v.62, p.499-505, 2003.

SAS INSTITUTE. SAS/STAT: user's guide. 4.ed. Cary: SAS Institute, 1989. (Version 6).

Recebido em 26 de outubro de 2007 e aprovado em 13 de março de 2008 